\title{
A 1400-YEAR OXYGEN ISOTOPE HISTORY FROM THE ROSS SEA AREA, ANTARCTICA
}

\author{
by
}

P.M. Grootes, M. Stuiver, T.L. Saling,

(Quaternary Isotope Laboratory, University of Washington, Seattle, WA 98195, U.S.A.)

P.A. Mayewski, M.J. Spencer,

(Glacier Research Group, University of New Hampshire, Durham, NH 03824, U.S.A.)

R.B. Alley,

(Earth Systems Science Center, Pennsylvannia State University, University Park, PA 16802, U.S.A.)

and

D. Jenssen

(Department of Meteorology, University of Melbourne, Parkville, Victoria 3052, Australia)

\section{ABSTRACT}

Four ice cores from the Ross Sea drainage, Antarctica, show patterns of $\delta^{18} \mathrm{O}$ variations on a time scale of decades to centuries over the last 1400 years without change in the long-term average $\delta^{18} \mathrm{O}$. Century scale $\delta^{18} \mathrm{O}$ fluctuations in the two cores drilled in the Ross Ice Shelf at Station J-9 $\left(82^{\circ} 23^{\prime} \mathrm{S}, 168^{\circ} 38^{\prime} \mathrm{W}\right.$, elevation $\left.60 \mathrm{~m}\right)$ are highly correlated $\left(\mathrm{P}<2 \times 10^{-4}\right)$. The long isotope record $(>30000 \mathrm{a})$ of the 1978 J-9 core thus represents local conditions over at least $10^{2} \mathrm{~m}$ and on time scales of 100 years and longer.

Regional correlations between the J-9 $\delta^{18} \mathrm{O}$ records and those from Ridge $\mathrm{BC}\left(82^{\circ} 54^{\prime} \mathrm{S}, 136^{\circ} 40^{\prime} \mathrm{W}\right.$, elevation $\left.509 \mathrm{~m}\right)$ and the Dominion Range $\left(85^{\circ} 15^{\prime} \mathrm{S}, 166^{\circ} 10^{\prime} \mathrm{E}\right.$, elevation $2700 \mathrm{~m}$ ) are barely significant $(\mathrm{P} \approx 0.05$ for $\mathrm{J}-9$ '76 and Dominion Range, 580 to 1400 years ago) or absent. The failure to find clear regional isotope trends related to climate fluctuations may reflect the finding that between 1957 and 1982 the area was in the transition zone between areas with opposite temperature trends, and showed little or no temperature change. The fact that the records nevertheless show significant $\delta^{18} \mathrm{O}$ fluctuations highlights the need to base regional climate reconstructions on a regional suite of ice-core records.

\section{INTRODUCTION}

The prospect of significant global warming over the next 50 to 100 years has generated intense interest in climate variability on time scales of decades to centuries. The question is whether the man-made increase in the atmospheric concentration of the greenhouse gases $\mathrm{CO}_{2}$ and $\mathrm{CH}_{4}$, which started roughly 150 years ago, has already resulted in a measurable climate change. Once a change is detected it can be used to calibrate the models that predict the future warming. As the anthropogenic climate change is the difference between the change observed and the change that would have occurred without human interference, its detection requires an accurate estimate of this natural climate change.

The polar regions are predicted to be most sensitive to a global warming. Climate observations in these areas are largely limited to the present century. Fortunately, the stable isotope ratio ${ }^{18} \mathrm{O} /{ }^{16} \mathrm{O}$ of firn and ice may provide a long and detailed proxy record of temperature. The value of the ${ }^{18} \mathrm{O} /{ }^{16} \mathrm{O}$ ratio as an inciicator of tine najor g'acial-inter- glacial climate changes is well established. However, the correlation between this ratio and temperature on time scales of decades to centuries, which is the time scale of the expected greenhouse warming, is not yet clear. The problem here is that although the signal-to-noise ratio of the actual isotope ratio measurement is high $(>10)$, factors other than temperature may lead to significant variations in the ${ }^{18} \mathrm{O} /{ }^{16} \mathrm{O}$ ratio (noise for the ${ }^{18} \mathrm{O} /{ }^{16} \mathrm{O}$ climate relation). Such factors may be changing surface topography leading to local maxima and minima of accumulation, shifts in balance between winter and summer accumulation, changes in firnification, etc. In this paper we try to determine whether the detailed ${ }^{18} \mathrm{O}$ records of four Antarctic cores contain a significant climate component.

\section{MATERIALS AND METHODS}

Four cores were obtained from the Ross Sea drainage of Antarctica (Table I, Fig. 1). The two J-9 cores were

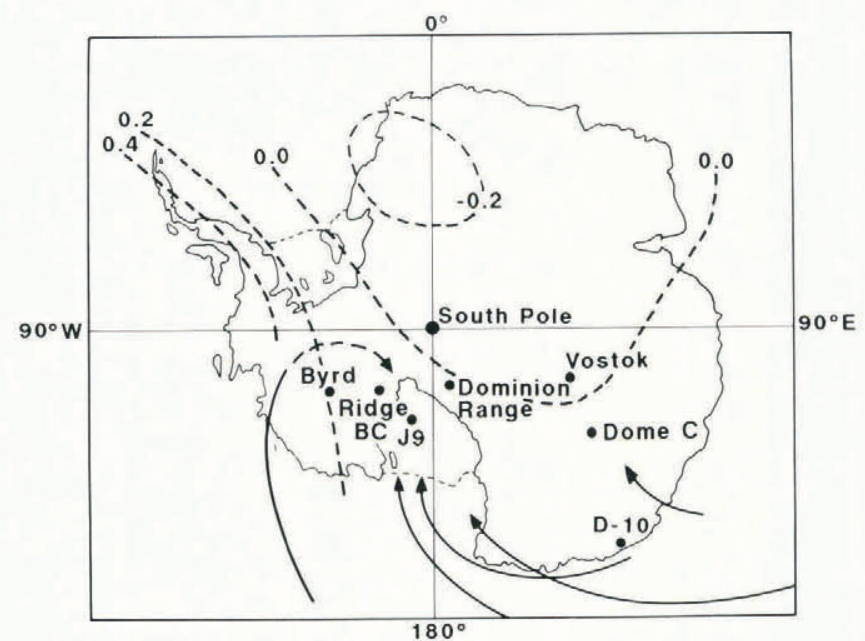

Fig. 1. Location of ice cores in Antarctica. Dashed lines give contours of factor loading of the first principal temperature change component in winter over the period 1957-82 from Raper and others (1984). Arrows give cyclonic paths (from Thompson and Mosley-Thompson, 1982). 
TABLE I. CORES FROM THE ROSS SEA DRAINAGE AREA

\begin{tabular}{|c|c|c|c|c|}
\hline Core & Drilled & Length & Location & Elevatio \\
\hline & & $\mathrm{m}$ & & 1 \\
\hline J-9 76 & 1976 & 100 & $82^{\circ} 23^{\prime} \mathrm{S}, 168^{\circ} 38^{\prime} \mathrm{W}$ & 60 \\
\hline J-9 78 & 1978 & 416 & $82^{\circ} 23^{\prime} \mathrm{S}, 168^{\circ} 38^{\prime} \mathrm{W}$ & 60 \\
\hline Ridge $B C$ & 1985 & 100 & $82^{\circ} 54^{\prime} \mathrm{S}, 136^{\circ} 40^{\prime} \mathrm{W}$ & 509 \\
\hline Dominion & & & & \\
\hline & 1984 & 200 & $85^{\prime} 15^{\prime} \mathrm{S}, 166^{\circ} 10^{\prime} \mathrm{E}$ & 2700 \\
\hline
\end{tabular}

drilled two years and about $100 \mathrm{~m}$ apart (personal communication from K. Kuivinen, 1989). These document spatial variability in the Ross Ice Shelf and test whether a single core represents conditions along its flow line at least over distances of $100 \mathrm{~m}$ (= "local conditions"). The cores from Ridge BC, West Antarctica, and the Dominion Range, Transantarctic Mountains, record conditions on both sides of the Ross Ice Shelf. The four core records together address the question of whether short term variability in the oxygen isotope records correlates significantly across the southern Ross Sea embayment, a regional correlation over distances of 500 to $700 \mathrm{~km}$. The J-9 1978 core (Grootes and Stuiver, 1986, 1987a) and the Dominion Range core (Mayewski and others, submitted) extend well into the last glacial period. Here we consider the last 1400 years of these records.
Annual accumulation for all cores is about $10 \mathrm{~cm}$ of water equivalent or less. To study climate variations on time scales of decades to centuries we chose a sampling interval of $50 \mathrm{~cm}$ for the J-9 cores and $25 \mathrm{~cm}$ for the others. Some sections were sampled in detail to determine fine structure and seasonal features. For those sections the data have been combined to $25 \mathrm{~cm}$ or $50 \mathrm{~cm}$ averages. The ${ }^{18} \mathrm{O} /{ }^{16} \mathrm{O}$ ratio of $5 \mathrm{ml}$ aliquots of the samples was measured using a Micromass 903 automated mass spectrometer with on-line water $/ \mathrm{CO}_{2}$ equilibration system. The results are expressed as $8^{18} \mathrm{O}$, the relative difference between the ${ }^{18} \mathrm{O} /{ }^{16} \mathrm{O}$ ratio of the sample and that of Standard Mean Ocean Water $(\mathrm{V}-\mathrm{SMOW})$, given in parts per mil $\left(\%_{\infty}\right)$. Standard deviation for a single measurement is less than $0.1 \%$. The $\delta^{18} \mathrm{O}$-depth profiles of the four cores are given in Figure 2.

The upper $35 \mathrm{~m}$ of the J-9 1978 core are missing. This core was drilled with ethanol antifreeze and the firn core dissolved in the drill fluid (Zotikov, 1979). The core was sampled in 1981. The dry-drilled 1976 core shows $\delta^{18} \mathrm{O}$ values increasing from $-29 \%$ at $50 \mathrm{~m}$ depth to about $-24 \%$ near the surface. The $-24 \%$ is much heavier than the value of $-29 \%$ reported for J-9 on the basis of snowpits and shallow cores (Clausen and others, 1979). Most likely the firn part of the 1976 core is significantly enriched due to water vapor loss during storage from 1976 to 1988 Transport of water vapor was evident at sampling from the fact that the $2 \%$ in diameter core was wedged tight and stuck in many of the 3 in inner diameter butyrate core tubes. The enrichment appears to decrease with increasing pore-close-off near the firn-ice transition (Fig. 2a). Below
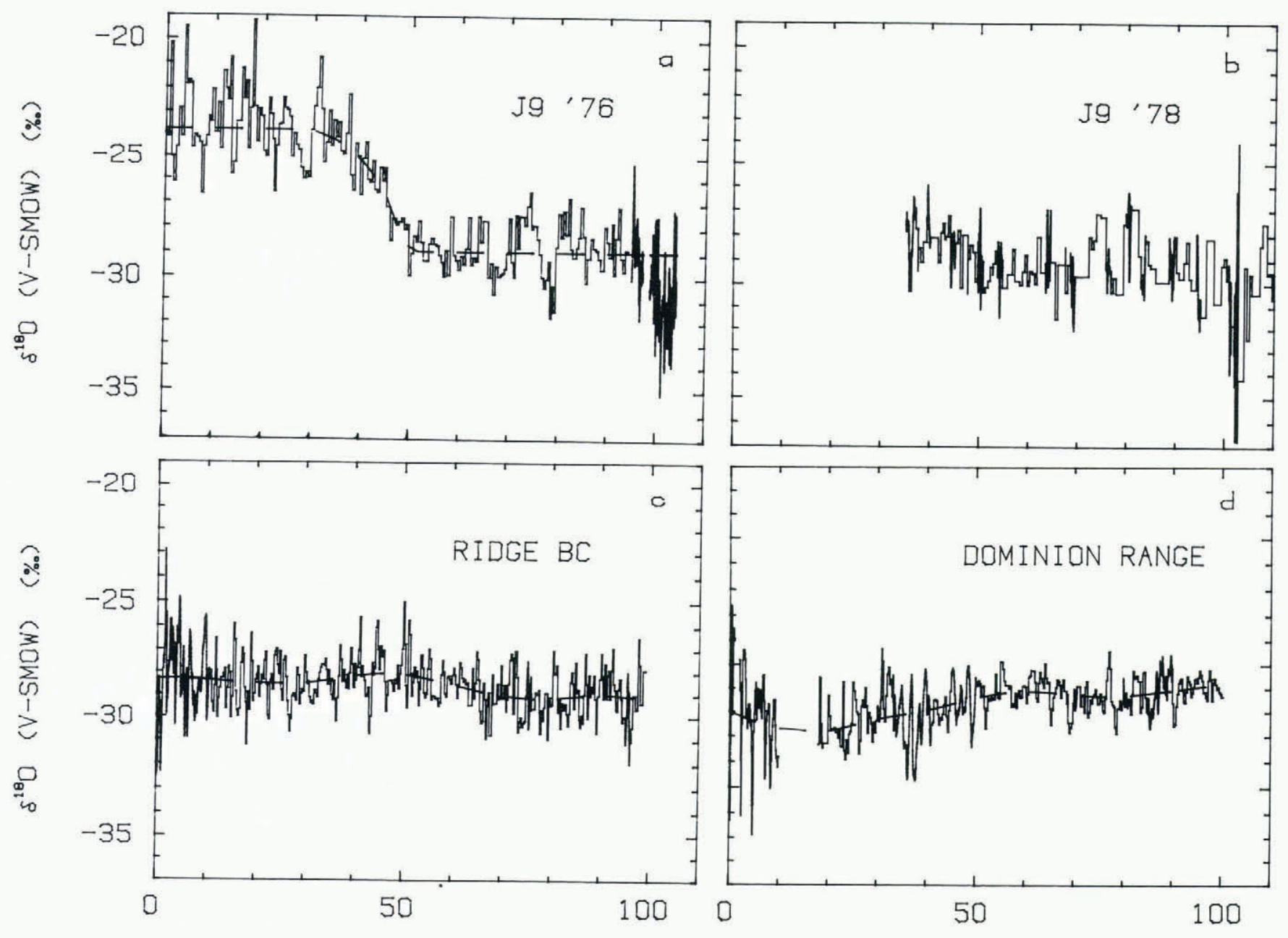

DEPTH (m)

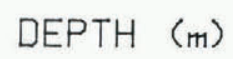

Fig. 2. The $\delta^{18} \mathrm{O}$-depth profiles of four ice cores from the Ross Sea drainage, Antarctica. Abscissa gives depth of core below the surface. (a) J-9 1976; (b) J-9 1978, upper section only; (c) Ridge BC; (d) Dominion Range, upper $96 \mathrm{~m}$ section only. A long-term trend in (a), (c) and (d) is removed by subtracting the dashed trendline from the data set. The increase in $\delta^{18} O$ in (a) occurs above the firn-ice transition and is enrichment of ${ }^{18} \mathrm{O}$ by water vapor loss during core storage. Gaps are due to missing core. 
$50 \mathrm{~m}$, in the ice, there are no signs of enrichment. The $\delta^{18} \mathrm{O}$ oscillations superimposed on the $\delta^{18} \mathrm{O}$ enrichment in the upper $50 \mathrm{~m}$ of J-9 1976 show no correlation with core breaks, and are therefore probably not caused by enrichment. It is thus likely that a valid record of shortterm $\delta^{18} \mathrm{O}$ variations can be obtained by removal of the enrichment trend as indicated (Fig. 2a).

Both the Ridge $\mathrm{BC}$ core and the Dominion Range core were sampled shortly after return of the ice from Antarctica. Though seasonal $\delta^{18} \mathrm{O}$ fluctuations may already be attenuated by smoothing via vapor phase diffusion during this time interval, $\delta^{18} \mathrm{O}$ values averaged over one or more years are still little affected (Grootes and Stuiver, 1987b). The long-term trends in the Ridge BC and the Dominion Range records are approximated by a best spline fit with $\sigma=0.93$ and 0.85 , respectively (Fig. $2 c$ and $2 d$ ).

\section{TIME SCALE}

The $\delta^{18} \mathrm{O}$-depth profiles must be converted to a $\delta^{18} \mathrm{O}$ time scale before the records can be compared. Since the seasonal $\delta^{18} \mathrm{O}$ cycle is not preserved during firnification in these low accumulation areas, the age-depth relation was based on ice flow modelling.

An age-depth relationship for J-9 was developed using the University of Melbourne ice flow model (Budd and others, 1984,1985$)$ for three different flow lines originating at different places at the West Antarctic ice divide and passing through Ice Stream B to J-9. Though the ages of the three models showed significant differences deeper in the core, they agreed reasonably well in the upper $100 \mathrm{~m}$. The age-depth relationship of a flow line, starting near the Whitmore Mountains, was used as time scale for both J-9 records.
The time scale for the Ridge $\mathrm{BC}$ core is based on the observed average near-surface accumulation (Alley and Bentley, 1988) and on vertical strain. The time scale for the Dominion Range core is based on a flow model using an average accumulation rate determined by gross beta activity and ${ }^{210} \mathrm{~Pb}$ measurements. This time scale was verified by matching a number of major acidity peaks with known volcanic eruptions (Spencer and others, this volume). The primary $\delta^{18} \mathrm{O}$ depth-interval data were converted to a $\delta^{18} \mathrm{O}$-time scale with single-year time steps, using interpolation where the measured depth intervals represented more than one year. Figure 3 gives the four records smoothed using a 5-year unweighted moving average to reduce noise.

\section{REGIONAL CORRELATIONS}

All four cores show multiple fluctuations in $\delta^{18} \mathrm{O}$ of $2-3 \%$ on a time scale of decades to centuries. No simple correlation is evident.

Our primary interest is to establish whether the cores record significant regional climate trends in the southern Ross Sea drainage. Such trends would produce a significant correlation between various cores. Significant correlation would be absent when local, non-climate-related $\delta^{18} \mathrm{O}$ variability dominates.

Cross correlation coefficients for the $\delta^{18} \mathrm{O}$ records were calculated using standard procedures (Bevington, 1969). To establish a significant correlation the probability $(\mathrm{P})$ that the same or a higher correlation coefficient is produced by chance by uncorrelated data sets must be less than 0.05 . P depends on the effective number of independent data points, and is thus dependent on the autocorrelation and the length of each record. Since the autocorrelation may differ

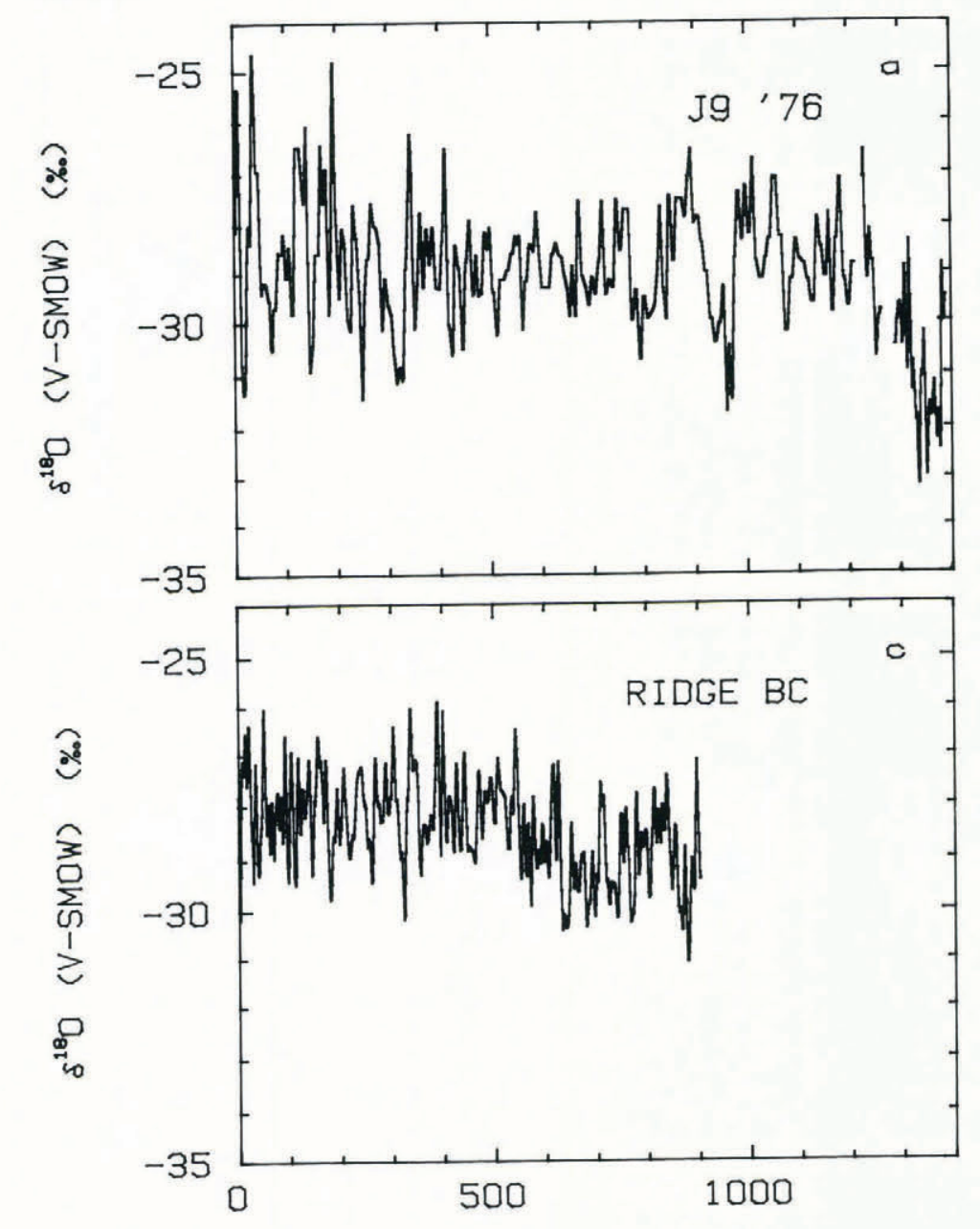

YEARS BEFORE DRILLING

Fig. 3. The $\delta^{18} \mathrm{O}$-time profiles of four ice cores from the Ross Sea drainage, Antarctica. Abscissa gives age of the ice in years before drilling based on ice flow modelling. (a) J-9 1976; (b) J-9 1978; (c) Ridge BC; (d) Dominion Range. The data have been smoothed with a 5-year unweighted moving average. Gaps are due to missing core. 
TABLE II. CROSS CORRELATIONS AND THEIR STATISTICAL SIGNIFICANCE FOR THE $\delta^{18} \mathrm{O}$ RECORDS OF FOUR ICE CORES FROM THE ROSS SEA DRAINAGE, ANTARCTICA

No smoothing

\begin{tabular}{|c|c|c|c|c|c|c|c|c|c|c|}
\hline \multirow[b]{2}{*}{ Period } & \multirow[b]{2}{*}{ Correlation } & \multicolumn{3}{|c|}{ No smoothing } & \multicolumn{3}{|c|}{$\begin{array}{l}5 \text {-year moving } \\
\text { average }\end{array}$} & \multicolumn{3}{|c|}{$\begin{array}{c}50 \text {-year moving } \\
\text { average }\end{array}$} \\
\hline & & $\mathrm{R}$ & $P$ & $1(\mathrm{yr})$ & $\mathbf{R}$ & $\mathbf{P}$ & $1(\mathrm{yr})$ & $\mathrm{R}$ & $P$ & $1(\mathrm{yr})$ \\
\hline \multirow[t]{3}{*}{$0-900 \mathrm{yr}$} & $\begin{array}{l}\text { J-9 } 76 \text {-Ridge BC } \\
\text { J-9 } 76 \text {-Dominion }\end{array}$ & -.143 & .031 & 20 & -.162 & 0.56 & 20 & -.228 & .218 & 14 \\
\hline & $\begin{array}{l}\text { Range } \\
\text { Ridge BC-Dominion }\end{array}$ & -.156 & .102 & 10 & -.159 & .150 & 8 & -.099 & .688 & -4 \\
\hline & Range & .158 & .034 & 18 & -.179 & .097 & 1 & -.395 & .162 & -30 \\
\hline \multirow[t]{3}{*}{$580-1400$} & $\begin{array}{l}\text { J-9 } 76-\mathrm{J}-9 \text { '78 } \\
\text { J-9 } \\
\text { '76-Dominion }\end{array}$ & .494 & .00017 & 0 & .573 & .00014 & -1 & .801 & .00019 & 4 \\
\hline & $\begin{array}{l}\text { Range } \\
\text { J-9' } 78-\text { Dominion }\end{array}$ & -.263 & .059 & -1 & -.286 & .063 & 2 & -.441 & .076 & 3 \\
\hline & Range & -.170 & .222 & 29 & -.188 & .221 & -30 & -.396 & .128 & -30 \\
\hline
\end{tabular}

$R$ : correlation coefficient.

P: probability that the same or a larger $\mathrm{R}$ is found by chance for two unrelated data sets.

1: lag for which the maximum correlation coefficient is obtained, $|1| \leqslant 30$. for different parts of a record, the shorter records have to be compared with corresponding sections of the long records.

Two time intervals are considered, 0 to 900 years and 580 to 1400 years. The first period represents the younger parts of the J-9 76 and Dominion Range records and the Ridge $\mathrm{BC}$ record. The second part is present in the two J-9 cores and the Dominion Range core. The interval 580 to 900 years is considered too short to include $\mathrm{J}-9$ ' 78 in the first or Ridge $\mathrm{BC}$ in the second group. The J-9 ' 76 record had to be detrended for ${ }^{18} \mathrm{O}$ enrichment during storage down to the firn-ice transition at about $50 \mathrm{~m}$ depth, 580 years. Therefore, we also removed the trends indicated in Figure 2 over the period 0 to 580 years from the Ridge $\mathrm{BC}$ and Dominion Range records in their comparison with J-9 '76. Correlation coefficients and their statistical significance were calculated for no smoothing, 5-year, and 50-year unweighted-moving-average smoothing. Results are summarized in Table II.

The correlation between the two J-9 cores over the time interval $580-1400$ years ago (50 to $104 \mathrm{~m}$ depth) is highly significant with $\mathrm{P}$ values from 1.4 to $1.9 \times 10^{-4}$. The correlation as function of lag shows a several-years-wide maximum which includes the 2-year lag expected from the drilling in 1976 and 1978. While the unsmoothed records have only $24 \%$ of their variance $\left(R^{2}\right)$ in common, this increases to $33 \%$ and $64 \%$ for 5 -year and 50 -year smoothing respectively, without seriously changing the significance of the correlation. This indicates that the $\delta^{18} \mathrm{O}$ fluctuations lasting about 100 years in the older part of the J-9 records (before 700 years ago) are the common features.

The apparent lack of correlation of the shorter $\delta^{18} \mathrm{O}$ fluctuations may have two causes, namely true local $\delta^{18} \mathrm{O}$ variability and/or time scale imperfections. Significant spatial $\delta^{18} \mathrm{O}$ variability over short distances may in areas of low accumulation result from sastrugi. Wind scouring and snow drifting can lead to uneven accumulation with missing years. Spatial $\delta^{18} \mathrm{O}$ variability may be enhanced after deposition by firnification processes in the near-surface snow especially if the snow resides near the surface for different lengths of time. The use of a flow-model-derived time scale may lead to an apparent lack of correlation, even if the spatial $\delta^{18} \mathrm{O}$ variability is low, when the local accumulation variations at the sites are uncorrelated. The resultant apparent shifts in timing are especially serious for the correlation of rapid fluctuations. The observed strong correlation between the two J-9 cores proves that the J-9 1978 core record, that extends back well over 30000 years (Grootes and Stuiver, 1986), is representative of local conditions (distance scale at least $100 \mathrm{~m}$ ) experienced by ice formed along the flowline down the West Antarctic ice sheet and through Ice Stream $\mathrm{B}$ over time periods of 100 years and longer.
A negative correlation based on long-term change in the older part of the J-9 1976 and Dominion Range records (580-1400 years) is indicated by the increase in correlation coefficient and common variance and the fairly constant $P$ values $(0.059$ to 0.076$)$ and lag under increasing smoothing. Although the strong correlation between the two J-9 cores makes one expect a similar correlation between J-9 1978 and the Dominion Range core none is found. The correlation coefficient is negative but too small to be significant. Over the last 900 years the correlation coefficient for J-9 1976 and the Dominion Range and Ridge BC cores is again negative, but it indicates only 1 to $5 \%$ common variance. A general correlation between records from the Ross Ice Shelf and the Transantarctic Mountains is expected from the general cyclonic air circulation moving from the Ross Sea over the Ross Ice Shelf and up the Transantarctic Mountains (Fig. 1, Thompson and Mosley-Thompson, 1982). The negative correlation between J-9 1976 and Ridge BC can be considered statistically significant ( $P$ of 0.031 and 0.056, constant lag). It must be based on short-term variability as it disappears under 50 year smoothing. The J-9 1976- Dominion Range correlation is likewise based on short term variability but the coefficient is not statistically significant. For the Ridge $\mathrm{BC}$ and Dominion Range cores the correlation coefficient changes from positive to negative and the optimum lag varies drastically. This and the higher $P$ values make a correlation between the two less likely.

\section{DISCUSSION}

The $\delta^{18} \mathrm{O}$ records of the two Ross Ice Shelf J-9 cores show a highly significant correlation on time scales of $10^{2}$ years or longer. Yet most of their rapid $\delta^{18} \mathrm{O}$ fluctuations do not contribute to the correlation coefficient and must be considered as noise in the climatic $\delta^{18} \mathrm{O}$ record.

The J-9, Ridge BC and Dominion Range records show a low common variance. The $\delta^{18} \mathrm{O}$ fluctuations in the records thus seem mostly unrelated to regional climate fluctuations in the southern Ross Sea drainage. Imperfections in the flow-model-derived time scales of the records may, however, have masked some of the shorter term regional covariance. Recent data on the covariance of temperature change in this area were obtained in a study of Antarctic temperature records over the period 1957 to 1982 by Raper and others (1984). Most snow accumulation seems to occur in winter so this period in the temperature analysis is most relevant for our records. During winter the first principal component, which explained $37 \%$ of the covariance, showed a transition zone from negative loadings in the area from $90^{\circ} \mathrm{E}$ to $40^{\circ} \mathrm{W}$ to positive loadings over the Antarctic Peninsula, located near the southern part of the Ross Sea 
drainage (Fig. 1). The time series of the second principal component, explaining $27 \%$ of the variance, does not show a clear trend over the 1957-82 period. Our failure to identify significant correlations between the different isotope records may thus simply indicate that the 1957-82 pattern of low sensitivity to Antarctic temperature change, detected by Raper and others (1984) for our area, also prevailed over the past 900 to 1400 years. Mosley-Thompson and others (this volume) reach a similar conclusion about the persistence of the current temperature variance pattern in the recent past in their discussion of the 550-year ice core record from Siple Station.

The results discussed in this paper highlight a serious problem in the climatic reconstruction from ice cores. The distinct isotope fluctuations on time scales of several years to many decades, that are observed in most detailed isotope records, do not necessarily all have climatic significance. Reliable reconstruction of regional climate change therefore requires the records of several cores, distributed over the region, with detailed time scales, such as can be obtained from seasonal cycles.

\section{ACKNOWLEDGEMENTS}

We thank the Polar Ice Coring Office (PICO) for drilling the Dominion Range and Ridge $\mathrm{BC}$ cores, and the U.S. Navy, ITT and NSF support staff for field support. The Central Ice Core Storage Facility staff at SUNY, Buffalo assisted in sampling the two J-9 cores. This research was funded by the U.S. National Science Foundation, Division of Polar Programs, under grants DPP 84-00574 and DPP 87-16102 to the University of Washington, DPP $84-11018$ to the University of New Hampshire, and DPP 83-15777 and DPP 85-21038 to the University of Wisconsin.

\section{REFERENCES}

Alley, R.B. and C.R. Bentley. 1988. Ice-core analysis on the Siple Coast of West Antarctica. Ann. Glaciol., 11, 1-7.
Bevington, P.R. 1969. Data reduction and error analysis for the physical sciences. New York, McGraw-Hill Book Co.

Budd, W.F., D. Jenssen, and I.N. Smith. 1984. A three-dimensional time-dependent model of the West Antarctic ice sheet. Ann. Glaciol., 5, 29-36.

Budd, W.F., D. Jenssen, and B.J. McInnes. 1985. Numerical modelling of ice stream flow with sliding. ANARE Res. Notes 28, 130-137.

Clausen, H.B., W. Dansgaard, J.O. Nielsen, and J.W. Clough. 1979. Surface accumulation on Ross Ice Shelf. Antarct. J. U.S., 14(5), 68-70.

Grootes, P.M. and M. Stuiver. 1986. Ross Ice Shelf oxygen isotopes and West Antarctic climate history. Quat. Res., 26(1), 49-67.

Grootes, P.M. and M. Stuiver. 1987a. Ice sheet elevation changes from isotope profiles. International Association of Hydrological Sciences Publication 170 (Symposium at Vancouver 1987 - The Physical Basis of Ice Sheet Modelling), 269-281.

Grootes, P.M. and M. Stuiver. 1987b. Isotopic alteration of firn cores. Antarct. J. U.S., 22(5), 79-80.

Mayewski, P.A., and 9 others. In press. The Dominion Range ice core, Queen Maud Mountains, Antarctica general site and core characteristics with implications. $J$. Glaciol.

Mosley-Thompson, E., L.G. Thompson, P.M. Grootes, and N. Gundestrup. 1990. Little ice age (neoglacial) paleoenvironmental conditions at Siple Station, Antarctica. Ann. Glaciol., 14, 199-204.

Raper, S.C.B., T.M.L. Wigley, P.R. Mayes, P.D. Jones, and M.J. Salinger. 1984. Variations in surface air temperatures. Part 3. The Antarctic, 1957-82. Mon. Weather Rev., 112, 1341-1353.

Spencer, M.J., P.A. Mayewski, W.B. Lyons, M.S. Twickler, J. Dibb, and P.M. Grootes. 1990. An 80-year ice chemistry record from the Dominion Range, Antarctica. Ann. Glaciol., 14,

Thompson, L.G. and E. Mosley-Thompson. 1982. Spatial distribution of microparticles with Antarctic snow-fall. Ann. Glaciol., 3, 300-306.

Zotikov, I.A. 1979. Antifreeze thermodrilling for core through the central part of the Ross Ice Shelf (J-9 camp), Antarctica. CRREL Rep. 79-24. 